\title{
Reducing Cracks and Delamination in Plasma-Sprayed Coatings of Calcia and Magnesia Stabilized- Zirconia.
}

\author{
Mohamed Hafez ${ }^{1}$, Sameh Akila ${ }^{1}$, Mohamed Khder ${ }^{1}$ and Ali Khalil ${ }^{2}$ \\ ${ }^{1}$ Department of Laser Sciences and Interactions, National Institute of Laser Enhanced Sciences, \\ Cairo University, Giza 21621, Egypt, ${ }^{2}$ Metallurgy and Mining Department, Tabbin Institute for \\ Metallurgical Studies, POB 109 Helwan, Cairo, Egypt
}

Ceramic materials for elevated temperature resistance applications should be selected to attain optimal microstructure and hardness. Zirconia (ZrO2)-based thermal barrier coatings (TBCs) deposited by atmospheric plasma spraying (APS) have received considerable attention because of its physical properties such as low thermal conductivity, high melting point, and high strength. Mechanical properties of TBCs are dependent principally on the resultant residual stresses that may relax to form cracks or the tendency to concentrate near the top of coat/bond interface, which can cause the coating to spall from the substrate [1-3]. Metal oxides are added to $\mathrm{ZrO} 2$ to stabilize the tetragonal and/or cubic phases at the ambient temperature conditions [4,5]. The use of well established commercial $\mathrm{ZrO} 2-\mathrm{CaO}$ and $\mathrm{ZrO} 2-\mathrm{MgO}$ ceramic powders provide coatings with an excellent ability to act as abrasion resistance and thermal load prevention layers. Establishing optimal spraying conditions to benefit from the distinct properties of calcium and magnesia-stabilized zirconia could have a significant effect on TBCs. This study gives an insight into microstructure development of the plasma-sprayed mixed powders of calcia and magnesia-stabilized zirconia and their mixture on 304 stainless steel substrate and its impact on the mechanical properties of the resulant coatings.

In the present work, three plasma-sprayed coating systems of $\mathrm{ZrO} 2-5$ wt. $\% \mathrm{CaO}, \mathrm{ZrO} 2-24$ wt.\% $\mathrm{MgO}$, in addition to their mixture were studied, designated here as CSZ, MSZ, and CSZ-MSZ, respectively. The powder used for the bond coating was Nickel Aluminium (Ni-5 wt.\% Al). And equal measured weights (50:50 ratio) of the two CSZ and MSZ powders were thoroughly mixed prior to spraying (CSZ-MSZ). A number of scans of the plasma torch were performed over the substrate to achieve the required top coating thickness. The thickness of the bond layer was prepared at approximately $50 \mathrm{~mm}$. The top coatings of the sustrates were sprayed at three selected plasma input currents of 600,650, and $700 \mathrm{~A}$. The microstructure and hardness of the as-sprayed coatings were characterized by scanning electron microscope (SEM), energy dispersive X-ray spectroscopy (EDX), and Rockwell hardness measurment.

Cross-sectional SEM in "Figure 1(a)" of the CSZ coating revealed a progressive crack along the interface of the top coating and the Ni-5Al bond coating. Mismatch in the coefficient of thermal expansion (CTE) of the coating components induced residual stresses, which act on a larger scale leading to the cracking of the coating. In addition to the effect of differences in the CTE, the oxide content in the sprayed coating may have a major role in affecting the bond strength. "Figure 1(b)" showed delamination that occurred between the top coat and the Ni-5Al layer. Because of increased residual stresses at the MSZ/Ni-5Al interface, crack growth reached a critical size that led to top coat delamination. On the other hand, the mixed CSZ-MSZ coating exhibited an adherent interface with the bond layer as seen in "Figure 1(c)". In Figure 2 (a) is SEM image of a mixed coating (CSZ-MSZ), which consists of several regions of different contrasts, this is due to the difference in the elemental ratios of these regions as indicated by the EDX spectra of these regions. Depicted in Figure 2(b) is the Rockwell hardness measurments of the mixed coating (CSZ-MSZ) at different plasma input current.

In conclusion, SEM and EDX analysis revealed modification of the top coating microstructure and the formation of different regions which is attributed to the differences in morphology and melting points of between the initial feeding particles of CSZ and MSZ powders. Investigation of the resultant mixed coating emphasized that mechanical properties of the coating are sensitive to the growth of oxide grains microstructures. The growth of these grains might provide a barrier for cracks that form due to induced stresses near and onto the bond layer and hence this results in reduced cracking, which in turn lessen or prevents the delamination of the coating. 
Acknowledgement: The authors would like to offer their special thanks to Prof. Saied Khalil and Prof. Adel Zahran, Tabbin Institute for Metallurgical Studies (TIMS), who, although no longer with us, but their insights, help and support throughout this investigation were greatly appreciated and will always be remembered.

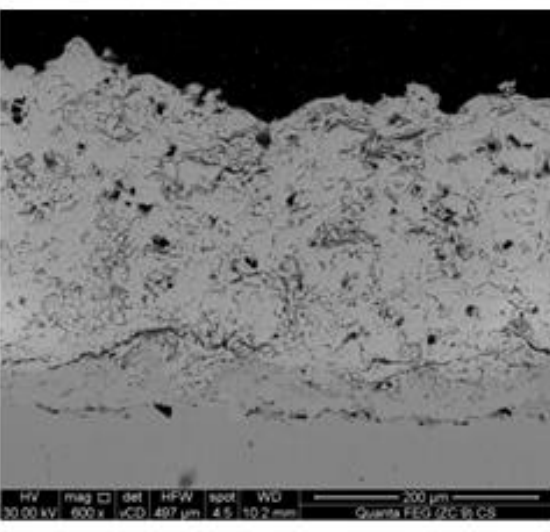

(a)

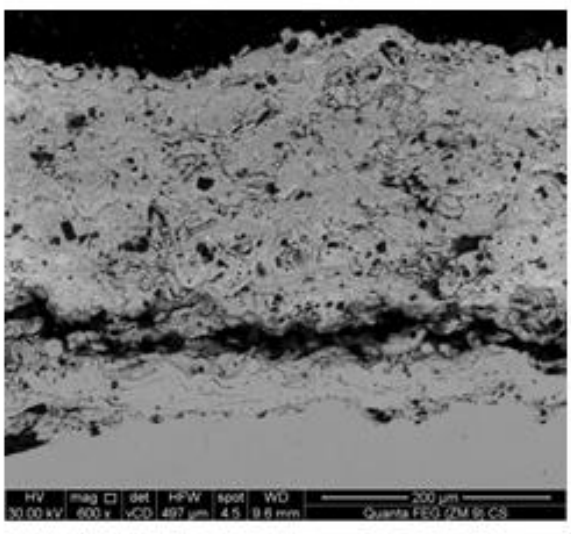

(b)

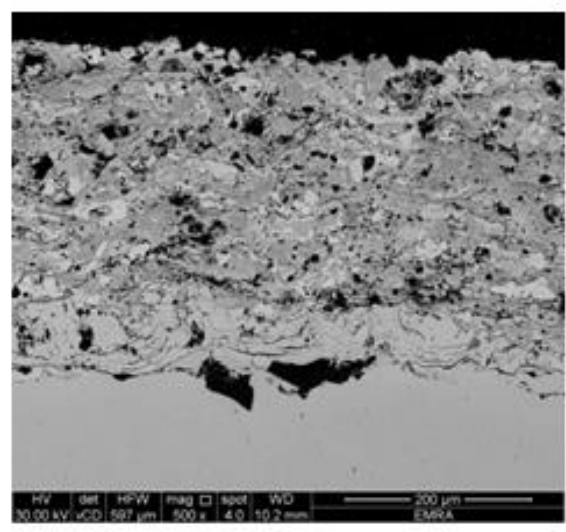

(c)

Figure 1. SEM images showing crack propagation and coating delamination of as-sprayed top coatings in (a) CSZ and (b) MSZ, respectively. (c) Adherent interface between the Ni-5Al bond coat and the top ceramic CSZ-MSZ mixed coating. The coating was at plasma current of $700 \mathrm{~A}$.

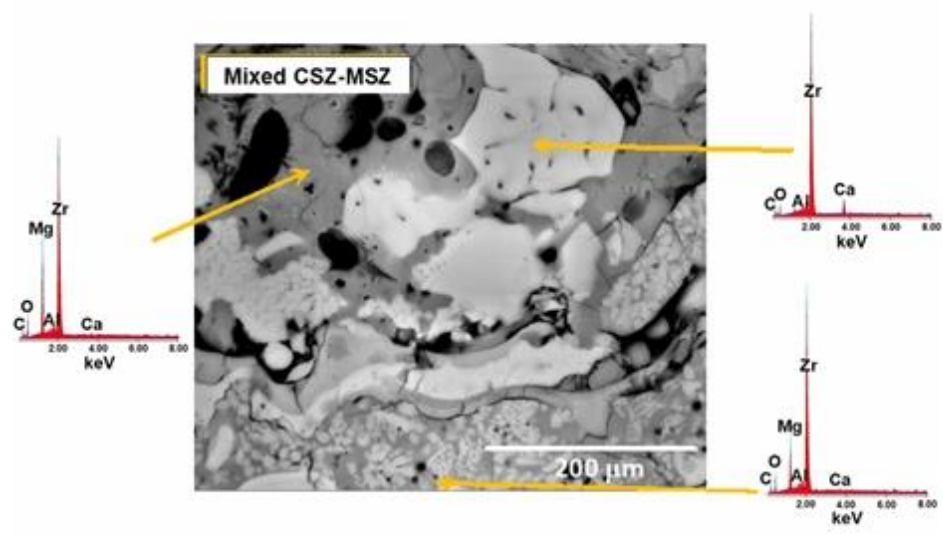

(a)

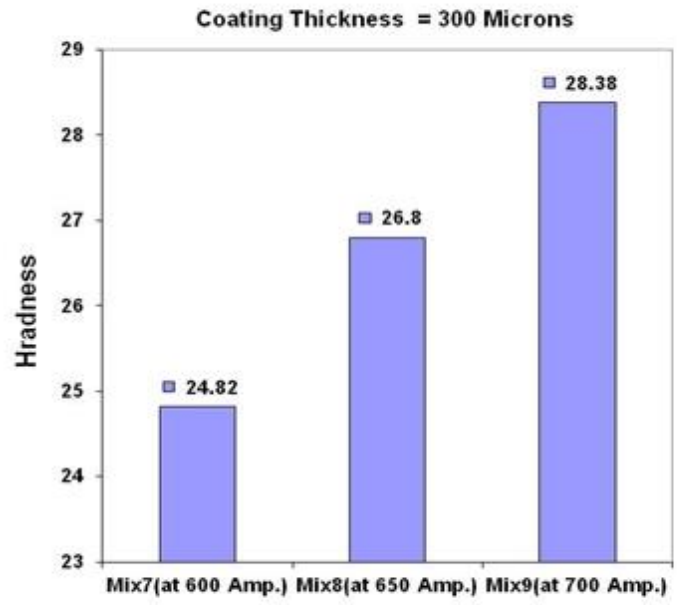

(b)

Figure 2. (a) SEM of mixed CSZ-MSZ coating as seen by the SEM. The EDX spectra were taken at selected regions. (b) Rockwell hardness of the mixed CSZ-MSZ top coats at thickness of $300 \mathrm{~mm}$ and at different plasma input current. The samples Mix 7, Mix 8, and Mix 9 were carried out at plasma input current of 600,650 , and $700 \mathrm{~A}$, respectively.

\section{References}


[1] T. W. Clyne and S. C., Gill Residual stresses in thermal spray coatings and their effect on interfacial adhesion: A review of recent work. J. Therm. Spray Technol. 5, 401-418 (1996).

[2] O. Kesler et al., Measurement of residual stress in plasma-sprayed metallic, ceramic and composite coatings. Mater. Sci. Eng. A 257, 215-224 (1998).

[3] J. Matejicek, S. Sampath, P. C. Brand, andH. J. Prask, Quenching, thermal and residual stress in plasma sprayed deposits: NiCrAlY and YSZ coatings. Acta Mater. 47, 607-617 (1999).

[4] R. S. Razavi and M. R. Loghman-Estarki, Advance Techniques for the Synthesis of Nanostructured Zirconia-Based Ceramics for Thermal Barrier Application. In: (ed. A. K. Mishra), Sol-gel Based Nanoceramic Materials: Preparation, Properties and Applications 21-91 (Springer, Cham, 2017).

[5] A. Bennett, Properties of thermal barrier coatings. Mater. Sci. Technol. 2, 257-261 (1986). 